\title{
A Novel Approach to Determine the Enriched Gas Recycling during the Enriched Gas Flooding Process
}

\author{
Yan Li, ${ }^{1}$ Chunsheng Yu ${ }^{D},{ }^{2}$ and Kaitao Yuan ${ }^{1}$ \\ ${ }^{1}$ Dingbian Oil Production Plant of Yanchang Oilfield Co., Ltd., China \\ ${ }^{2}$ Southwest Petroleum University, China \\ Correspondence should be addressed to Chunsheng Yu; yuchunsheng_2000@163.com
}

Received 19 October 2021; Revised 3 December 2021; Accepted 21 December 2021; Published 14 January 2022

Academic Editor: Qingwang Yuan

Copyright (C) 2022 Yan Li et al. This is an open access article distributed under the Creative Commons Attribution License, which permits unrestricted use, distribution, and reproduction in any medium, provided the original work is properly cited.

\begin{abstract}
A novel approach was proposed for calculating the enriched gas recovery factor based on the theory of two-phase isothermal flash calculations. First, define a new parameter, pseudo formation volume factor of enriched gas, to represent the ratio of the surface volume of produced mixture gas to underground volume of enriched gas. Two logarithmic functions were obtained by matching the flash calculation data, to characterize the relationships between pseudo formation volume factor and the produced gas-oil ratio. These two functions belong to the proportion of liquefied petroleum gas in enriched gas; the proportion is greater than $50 \%$ and less than 50\%, respectively. Given measured gas-oil ratio and produced gas volume, underground volume of produced enriched gas can be calculated. Injection volume of enriched gas is known; therefore, recovery factor of enriched gas is the ratio of produced to injected volume of enriched gas. This approach is simply to calculate enriched gas recovery factor, because of only needs three parameters, which can be measured directly. New approach was compared to numerical simulation results; mean error is $12 \%$. In addition, new approach can effectively avoid the influence of lean gas on the calculation of enriched gas recycling. Three stages of enriched gas recovery factors in field $\mathrm{Z}$ were calculated, and the mean error is 5.62\% compared to the field analysis, which proves that the new approach's correctness and practicability.
\end{abstract}

\section{Introduction}

Tight sandstone reservoirs are widely distributed in China. However, they are characterized by low permeability, complex pore structures, and high ratio of nano- to micropore radius, which results in poor development efficiency and low primary recovery [1-3]. As one of the main technologies of tertiary oil recovery, gas flooding has been successfully applied in many oilfields and shows a good performance $[4,5]$. Gas injection EOR technologies that have been employed in industrial applications mainly include carbon dioxide flooding, air flooding, nitrogen flooding, hydrocarbon gas flooding, and flue gas flooding [6-8]. Enriched gas is a kind of hydrocarbon gas mixed by natural gas (NG) and liquefied petroleum gas (LPG) in a certain proportion. The purpose is to reduce the minimum miscible pressure of natural gas and crude oil by mixing with LPG.

The first field test of LPG miscible flooding was implemented in 1956, and the oil recovery was increased by more than $12 \%[9,10]$. Breakthrough of continuous gas injection is the key challenge that affects oil recovery $[11,12]$. Produced gas reinjection is one commonly used technology $[13,14]$. Yang et al. [15] analyzed the mixture of $\mathrm{CO}_{2}$ and dissolved gas reinjection by conducting computed tomography (CT) scan experiments, and it revealed that $\mathrm{CO}_{2}$ content determines the extent of enhanced oil recovery. Chen et al. [16] studied the influence of $\mathrm{CO}_{2}$ content in the reinjected mixture gas on the near miscible pressure through slim tube experiments. Only when the $\mathrm{CO}_{2}$ content reached a certain proportion could the near miscible flooding of the reinjected gas be occurred [17]. The mentioned above studies show that $\mathrm{CO}_{2}$ content in the reinjected mixture gas determines the oil recovery efficiency. Similarly, a certain proportion of enriched gas is needed to achieve efficient development. The gas produced from the process of enriched gas flooding is a mixture of solution gas and enriched gas; in addition, the ratio of enriched gas to solution gas in the mixture varies along with the reservoir heterogeneity, well pattern, and well 
spacing. Therefore, it is difficult to obtain the accurate value for enriched gas recovery (EGR).

EGR is usually measured indoor by using gas chromatography (GC) or mass spectrometry (MS) [18-20] but not applied to the field. Flash calculation is one of the basic constituents of gas-liquid equilibrium calculation, which is used to calculate the compositional ratio of gas phase to the liquid phase at a given temperature, and pressure provided the total composition of the system is known [21-23]. Lee et al. [19] quantified the mass transfer mechanism in a rich-gas injection EOR process. Subsequently, combined with the molar composition of injected LPG and dry gas, the overdetermined equations were established, and the LPG quantity was calculated by the least square method. This method requires that the composition of the produced gas is known. However, the fact is that the produced gas composition always varies with time, which implies that this calculation method is debatable. In this paper, a novel approach was proposed to calculate the EGR factor based on the theory of two-phase isothermal flash calculation. Two logarithmic functions were obtained by matching the flash calculation data, which characterizes the relationships between pseudo formation volume factor (PFVF) and the produced gas-oil ratio (GOR). Given the value of GOR and produced gas volume, underground volume of produced enriched gas can be calculated. The volume of injected enriched gas is known; therefore, EGR is the volumetric ratio of produced to injected enriched gas. Our new approach only needs three parameters, i.e., GOR, produced gas volume, and injected enriched gas volume, which can be measured directly in field enriched gas flooding process. Thereby, this method can be easily used by reservoir engineers. In order to prove the validity of our novel approach, numerical simulation results were compared, and the mean error is $12 \%$. In addition, the new approach can effectively avoid the influence of lean gas on the calculation of enriched gas recycling. Three stages of enriched gas recovery factors in field $\mathrm{Z}$ were calculated, and the mean error is $5.62 \%$ compared to the field analysis, which proves that the new approach's correctness and practicability.

1.1. Isothermal Flash Calculation Theory. Flash separation is known as contact separation or one-time degassing [24]. This separation method mimics the process when the produced oil and gas enter the separator at one time or directly into the large tank for degassing. Oil and gas reach equilibrium instantly, and the separated gas and oil always stay in contact during the separation process, which means that the total composition of the system remains unchanged (Figure 1).

Two-phase flash calculation method is widely adopted in the existing software of compositional model. And this method excludes the water phase and calculates the oil-gas two-phases flash separation of the mixture [25].

One mole of mixture with known composition reaches phase equilibrium at specific temperature and pressure and separates into two phases, i.e., oil and gas. The basic equations describing this process are as follows.

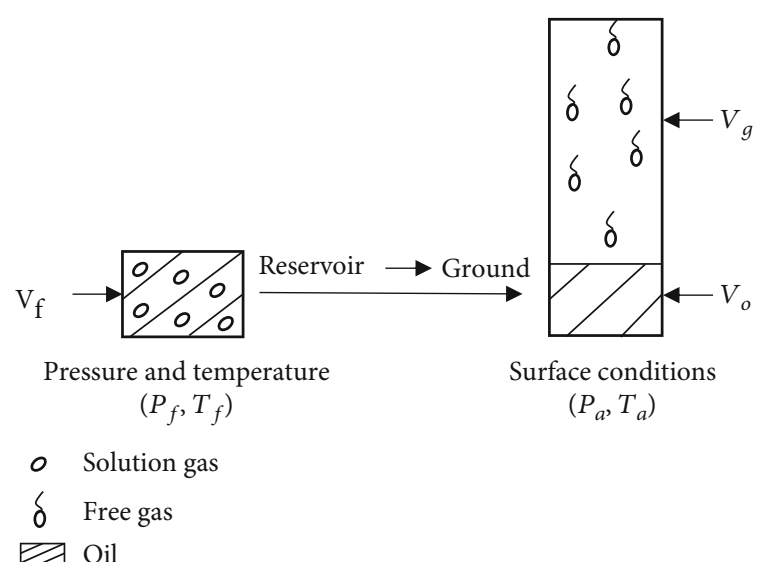

FIGURE 1: Flash separation schematic diagram.

Total material conservation is expressed as

$$
L+V=1
$$

where $L$ represents molar composition of oil phase and $V$ is molar composition of gas phase.

The material conservation of component $i$ is expressed as

$$
L x_{i}+V y_{i}=z_{i}(i=1,2, \cdots, n)
$$

where $x_{i}$ is the mole fraction of component $i$ in oil phase, $y_{i}$ is the mole fraction of component $i$ in gas phase, $z_{i}$ is the total mole fraction in the mixture of oil and gas, and $n$ is the number of components.

When the hydrocarbon system reaches phase equilibrium, the fugacity of each component in the system is equal in gas and liquid phases

$$
f_{i L}=f_{i V}(i=1,2, \cdots, n),
$$

where $f_{i L}$ and $f_{i V}$ are fugacities of component $i$ in oil and gas phases, respectively.

The constraint equation is

$$
\sum_{i=1}^{n} x_{i}=1(i=1,2, \cdots, n) .
$$

Equations (1) to (4) contain $(2 n+2)$ functions, which have $(2 n+2)$ unknowns. Fugacity of component $i$ is calculated by the Peng-Robinson equation of state [26].

1.2. EGR Model. Underground volume of enriched gas $V_{y}$ in a mixture under formation pressure and temperature can be calculated by the two-phase flash calculation method. The surface volume $V_{y s}$ and GOR of the separated gas are calculated by flashing the mixture to surface conditions.

The PFVF of the enriched gas is defined as $B_{y}$

$$
B_{y}=\frac{V_{y}}{V_{y s}} .
$$


TABLE 1: Flash calculation results of PFVF and GOR of different composition of enriched gas mixed with crude oil in different proportions.

\begin{tabular}{|c|c|c|c|c|c|c|}
\hline \multirow{2}{*}{ Enriched gas (LPG: NG, \%) } & \multirow{2}{*}{ Flash calculation parameters } & \multicolumn{5}{|c|}{ Composition of reservoir fluids (oil : enriched gas, \%) } \\
\hline & & $95: 5$ & $90: 10$ & $80: 20$ & $50: 50$ & $10: 90$ \\
\hline \multirow{2}{*}{$59.1: 40.9$} & $B_{y} / 10^{-3}$ & 0.831 & 1.164 & 1.577 & 3.207 & 4.565 \\
\hline & $\mathrm{GOR} / \mathrm{sm}^{3} / \mathrm{rm}^{3}$ & 63.82 & 73.97 & 94.19 & 415.09 & 1650.44 \\
\hline \multirow{2}{*}{$51: 49$} & $B_{y} / 10^{-3}$ & 0.869 & 1.196 & 1.663 & 3.301 & 4.635 \\
\hline & $\mathrm{GOR} / \mathrm{sm}^{3} / \mathrm{rm}^{3}$ & 64.02 & 74.1 & 95.86 & 421.55 & 1694.875 \\
\hline \multirow{2}{*}{$41: 59$} & $B_{y} / 10^{-3}$ & 0.983 & 1.807 & 3.085 & 5.163 & 6.156 \\
\hline & $\mathrm{GOR} / \mathrm{sm}^{3} / \mathrm{rm}^{3}$ & 65.06 & 76.53 & 99.72 & 433.34 & 1758.36 \\
\hline \multirow[b]{2}{*}{$37.1: 62.9$} & $B_{y} / 10^{-3}$ & 0.983 & 1.407 & 2.085 & 4.163 & 6.156 \\
\hline & $\mathrm{GOR} / \mathrm{sm}^{3} / \mathrm{rm}^{3}$ & 65.32 & 77.07 & 100.87 & 436.96 & 1779.44 \\
\hline \multirow{2}{*}{$35.2: 64.8$} & $B_{y} / 10^{-3}$ & 0.991 & 1.419 & 2.101 & 4.188 & 6.307 \\
\hline & $\mathrm{GOR} / \mathrm{sm}^{3} / \mathrm{rm}^{3}$ & 65.45 & 77.33 & 101.42 & 438.69 & 1789.46 \\
\hline \multirow{2}{*}{$34.8: 65.2$} & $B_{y} / 10^{-3}$ & 0.997 & 1.429 & 2.117 & 4.215 & 6.343 \\
\hline & $\mathrm{GOR} / \mathrm{sm}^{3} / \mathrm{rm}^{3}$ & 65.47 & 77.39 & 101.54 & 439.05 & 1791.55 \\
\hline
\end{tabular}

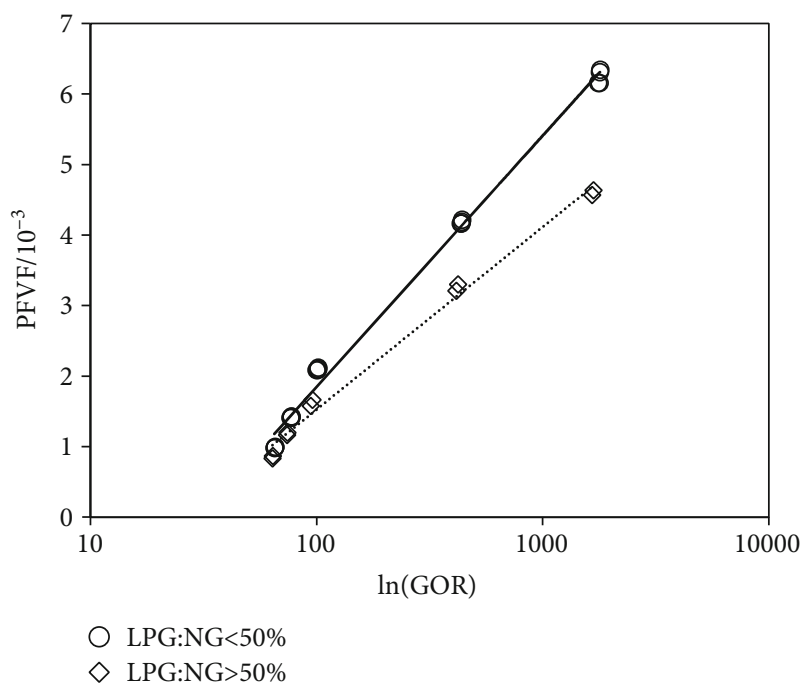

FIGURE 2: Relationships between PFVF and GOR. The dashed line indicates LPG : NG > 50\%, and the solid line is LPG : NG $<50 \%$.

Due to the miscible or near miscible characteristics of enriched gas contacts with crude oil, C3-C4 hydrocarbons in enriched gas constantly dissolve into crude oil, and light components in crude oil are extracted to free gas. This phenomenon results in complex composition of produced gas, which cannot be simply treated as a mixture of enriched gas and solution gas $[6,27]$. Therefore, $B_{y}$ is not the real formation factor of enriched gas, so it is named as pseudo formation volume factor.

PFVF and GOR are intrinsically related to each other; hence, functional relationships between $B_{y}$ and GOR are given by

$$
B_{y}=F(\mathrm{GOR})
$$

So far, given the GOR, that the PFVF $B_{y}$ can be calculated by equation (6). In the real oilfield production process, the gas
TABLE 2: Comparison of expansion coefficients.

\begin{tabular}{lcccc}
\hline & $\begin{array}{c}\text { Enriched } \\
\text { gas } \\
\text { Block }\end{array}$ & \multicolumn{3}{c}{ Expansion coefficient } \\
& $\begin{array}{c}\text { LPG:NG, } \\
\%)\end{array}$ & $\begin{array}{c}\text { Measured } \\
\text { values }\end{array}$ & $\begin{array}{c}\text { Calculated } \\
\text { values }\end{array}$ & $\begin{array}{c}\text { Rel. } \\
\text { error/\% }\end{array}$ \\
\hline \multirow{2}{*}{ IV } & $59.8: 40.2$ & 199.86 & 217.51 & 8.83 \\
& $41: 59$ & 159.63 & 170.35 & 6.72 \\
& $37.1: 62.9$ & 150.22 & 159.25 & 6.02 \\
\hline \multirow{2}{*}{ IA-top } & $59.8: 40.2$ & 150.815 & 151.208 & 0.26 \\
& $41: 59$ & 142.717 & 145.779 & 2.15 \\
\hline IA- & $59.8: 40.2$ & 239.69 & 257.756 & 7.54 \\
bottom & $41: 59$ & 197.965 & 207.562 & 4.85 \\
\hline
\end{tabular}

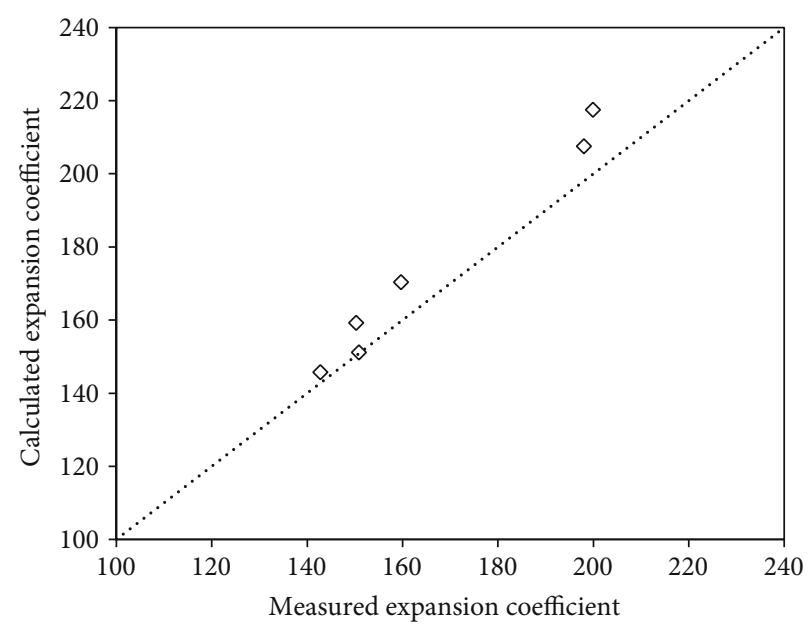

FIgURE 3: Comparison of calculated expansion coefficient against the measured values. The dashed lines indicate relative errors equal to zero. 
TABle 3: Parameter design of numerical simulation model.

\begin{tabular}{|c|c|c|c|c|c|c|c|}
\hline $\begin{array}{l}\text { Grid } \\
\text { direction }\end{array}$ & $\begin{array}{c}\text { Grid } \\
\text { numbers }\end{array}$ & $\begin{array}{c}\text { Step size/ } \\
\mathrm{m}\end{array}$ & $\begin{array}{l}\text { Permeability/ } \\
\mathrm{mD}\end{array}$ & $\begin{array}{l}\text { Porosity/ } \\
\%\end{array}$ & $\begin{array}{c}\text { Oil saturation/ } \\
\%\end{array}$ & $\begin{array}{c}\text { Formation pressure/ } \\
\mathrm{MPa}\end{array}$ & $\begin{array}{c}\text { Saturated pressure/ } \\
\mathrm{MPa}\end{array}$ \\
\hline$X$ & 150 & 1 & 1.09 & & & & \\
\hline$Y$ & 1 & 100 & 1.09 & 11.05 & 41.35 & 10.5 & 10.2 \\
\hline$Z$ & 7 & 3.1 & 0.107 & & & & \\
\hline
\end{tabular}

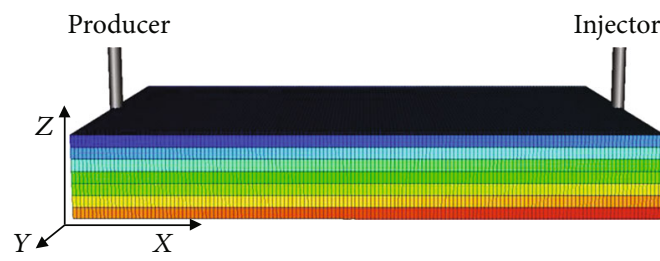

FIgURE 4: The 3D grid model of reservoir simulation.

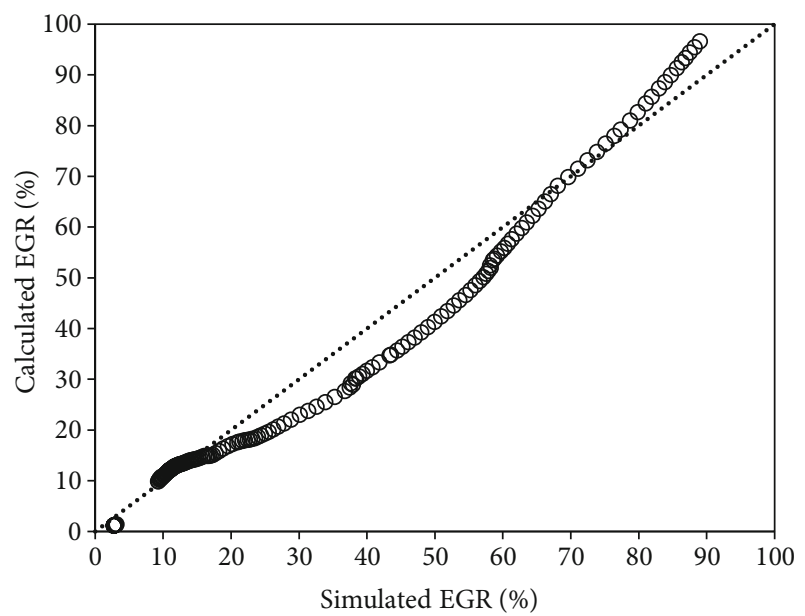

FIGURE 5: Comparison of calculated EGR against the simulated values, $\mathrm{LPG}: \mathrm{NG}<50 \%$. The dashed lines indicate relative errors equal to zero.

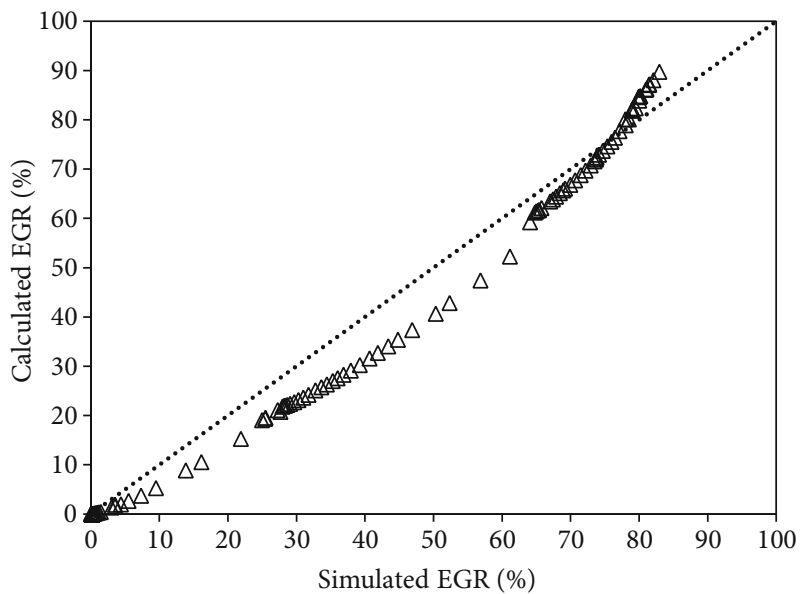

FIGURE 6: Comparison of calculated EGR against the simulated values, LPG : NG $>50 \%$. The dashed lines indicate relative errors equal to zero.

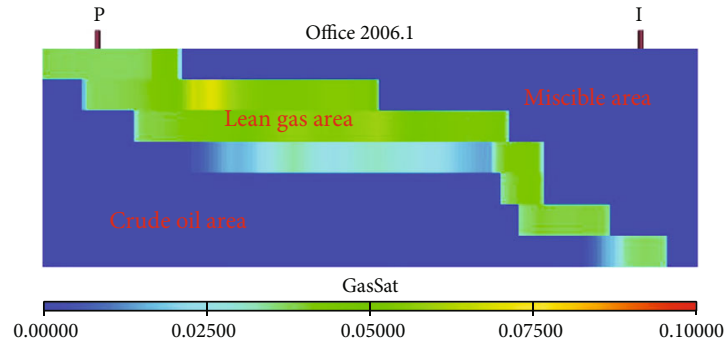

Figure 7: Gas saturation profile of enriched gas flooding.

volume $V_{y s}$ produced from wellhead can be measured; thereby, the underground enriched gas volume $V_{y}$ can be obtained through equation (5). Injected volume of enriched gas $V_{g I}$ is known; finally, enriched gas recovery $R_{g}$ can be calculated as

$$
R_{g}=100 \times \frac{V_{y}}{V_{g I}}
$$

The above analysis shows that key point to calculate EGR factor is to obtain the functional relationships between the PFVF of enriched gas and the produced GOR. In the following, the way to obtain the functional relationships is delineated, and one application to an enriched gas flooding in tight sandstone reservoir is provided.

Taking the enriched gas flooding in oilfield $\mathrm{Z}$ as an example, the reservoir pressure is $10.5 \mathrm{MPa}$, formation temperature is $34.2^{\circ} \mathrm{C}$, and the average permeability is $1.09 \mathrm{mD}$. Six proportions of enriched gas were tested in the laboratory, and the molar ratios of LPG to natural gas are 59.1:40.9, $51: 49,41: 59,37.1: 62.9,35.2: 64.8$, and $34.8: 65.2$, respectively. In pilot test, three proportions of enriched gas were implemented; they are 59.8:40.2, 41:59, and 37.1:62.9, respectively. Due to the influence of formation heterogeneity, enriched gas is not evenly distributed in the formation during gas flooding. Consequently, the produced GOR will vary with time. Therefore, the PFVF and GOR were calculated by different crude oil to enriched gas ratios. Molar ratios of crude oil to enriched gas are $95: 5,90: 10,80: 20$, $50: 50$, and $10: 90$, respectively. Flash calculation results are shown in Table 1.

In order to obtain the functional relationships between PFVF and GOR, a relationship diagram (Figure 2) was drawn. From Figure 2, the following conclusions can be obtained: PFVF increases with GOR; when the proportion of LPG in the enriched gas is more than $50 \%$, the PFVF and the GOR follow a logarithmic relationship; when the proportion of LPG in the enriched gas is less than $50 \%$, the 
TABLE 4: Injection and production data of enriched gas flooding in the field $\mathrm{Z}$ and calculated EGRs.

\begin{tabular}{|c|c|c|c|c|c|c|c|}
\hline Injection stage & $\begin{array}{c}\text { Enriched gas } \\
(\mathrm{LPG}: \mathrm{NG}, \%)\end{array}$ & Injection volume $\left(\mathrm{rm}^{3}\right)$ & GOR & Produced gas $\left(10^{3} \mathrm{~m}^{3}\right)$ & $\operatorname{PFVF}\left(10^{-3}\right)$ & Production volume $\left(\mathrm{rm}^{3}\right)$ & EGR (\%) \\
\hline Stage 1 & $59.8: 40.2$ & 145.8 & 883 & 19.35 & 4.26 & 82.48 & 56.57 \\
\hline Stage 2 & $41: 59$ & 479.5 & 370 & 66.91 & 4.29 & 287.21 & 59.89 \\
\hline Stage 3 & $37.1: 62.9$ & 556.9 & 950 & 71.38 & 5.68 & 405.06 & 72.73 \\
\hline
\end{tabular}

PFVF and GOR follow another logarithmic relationship. When the proportion of LPG in the enriched gas in more than $50 \%$, the relative volume increases slightly than LPG proportion is less than $50 \%$; this is mainly because the higher LPG proportion is, the more easily miscible flooding occurred. $50 \%$ of LPG in enriched gas was used as the demarcation point in this research; it is related to the composition of crude oil and the reservoir situations (temperature and pressure).

Based on Figure 2, logarithmic fitting method is adopted to obtain the functional relationships between PFVF and GOR when the proportion of LPG is less than $50 \%$ and more than $50 \%$ in enriched gas, respectively, as described in equations (8) and (9). In addition, the fitting precisions of equations (8) and (9) are 0.9943 and 0.9922, respectively, which meet the needs of engineering application.

$$
\begin{gathered}
B_{y 1}=1.547 \ln \left(\mathrm{GOR}_{1}\right)-5.2768, \\
B_{y 2}=1.124 \ln \left(\mathrm{GOR}_{2}\right)-3.6497
\end{gathered}
$$

\section{Results and Discussion}

2.1. Comparison of Expansion Coefficients. In order to verify the robustness of our flash calculation method, we compared the expansion coefficient of enriched gas between measured values and calculated ones. Measured values were taken from the pilot test of enriched gas miscible flooding in oilfield $\mathrm{Z}$ of Algeria. Miscible flooding was carried out in three blocks, block IV, block IA-top, and block IA-bottom. Expansion coefficient is the reciprocal of the formation volume factor of enriched gas under standard conditions. As shown in Table 2, the calculated error for different proportions of LPG in enriched gas is between 4 and $8 \%$. From Figure 3, it indicates that the calculated expansion coefficients are slightly higher than measured values. This is probably because the actual measured pressure and temperature may be lower than the calculated value due to the pressure and temperature loss of the measuring instrument, resulting in low measurement results. The relative error increases with the increase of LPG proportion. The underlying reason is that as the proportion of LPG increases, the percentage of C3-C4 increases in enriched gas, and its compressibility is greater than that of natural gas, thus magnifying the calculation error.

2.2. Comparison of EGR Calculation Results and That from Numerical Simulations. Numerical simulation model was established to simulate the EGR factors with different injected LPG:NG proportions. The Eclipse composition simulator v2006 of Schlumberger was used for numerical simulation, which can simulate multicomposition flash calculation and enriched gas flooding. A number of grids in the directions of $X, Y$, and $Z$ are 150,1 , and 7 , respectively, and the step sizes are 1,100 , and 3.1 meters, respectively. The model represents a tight sandstone reservoir with the average permeability of $1.09 \mathrm{mD}$, and porosity is $11.05 \%$. Other parameters of the model are shown in Table 3, and Figure 4 is the three-dimensional grid model.

Two scenarios were simulated, i.e., scenario 1 and scenario 2 . The injected proportion of $\mathrm{LPG}: \mathrm{NG}$ of scenario 1 is $41: 59$, which represents that the LPG : NG $<50 \%$, and equation (8) is employed to calculate EGR. Scenario 2 with LPG:NG is 59:41, which indicates the LPG : NG > 50\%, and equation (9) is used to calculate EGR. Enriched gas injection volumes of the both scenarios are $100 \mathrm{rm}^{3} / \mathrm{d}$; minimum bottom hole pressure of production well is slightly higher than saturation pressure to ensure that solution gas is not released.

Numerical simulation results and calculated values are compared in Figures 5 and 6, respectively. Mean errors are $11.22 \%$ and $12.21 \%$ for Figures 5 and 6, respectively. Error analysis shows that when EGR is less than $10 \%$, the errors of both functions are greater than $50 \%$. The main reason is that the proposed approach is based on the flash calculation theory. However, the numerical simulation approach takes account of the dynamic process of light hydrocarbon extraction and heavy hydrocarbon dissolution. As shown in Figure 7 , gas saturation profile falls into three regions. The first region corresponds to the miscible process of crude oil and enriched gas. The second one is lean gas area which is extracted from crude oil, and the third one is crude oil area. Because of the light hydrocarbon extracted from the crude oil, EGR is high in the early stage of enriched gas flooding. In this stage, lean gas is mainly produced, and C3-C4 are not largely produced. In other words, the proposed approach avoids the influence of lean gas production on the calculation of EGR in the early stage of enriched gas flooding.

2.3. Field Application. The production data of the pilot test with one injection well and one production well in oilfield $\mathrm{Z}$ was used to calculate the EGR. Table 4 displays the injection and production performance of the three stages' enriched gas injection. According to the molar composition of injected enriched gas, equation (9) was used to calculate the enriched gas PFVF in the first stage, and equation (8) was used to calculate the enriched gas PFVF in the second and third stages. Enriched gas PFVFs in the first, second, and third stages were calculated to be $4.26 \times 10^{-3}, 4.29 \times$ $10^{-3}$, and $5.68 \times 10^{-3}$, respectively. Given the PFVFs of enriched gas, the underground volumes of enriched gas 
produced in three stages are calculated according to the gas production from wellhead in each stage, and the underground volumes are $82.48 \mathrm{rm}^{3}, 287.21 \mathrm{rm}^{3}$, and $405.06 \mathrm{rm}^{3}$, respectively. Thus, the EGRs in three stages are $56.57 \%$, $59.89 \%$, and $72.73 \%$, respectively, with an average value of $63.07 \%$. EGR of three gas injection stages obtained by chromatographic analysis in the field is $59.71 \%$, and the error between the approach proposed in this paper and the results from the field is $5.62 \%$.

A simple approach is proposed in this article to calculate the EGR of unconventional reservoir enriched gas displacement. It should be noted that the functional relationships between PFVF and GOR are not applicable to all reservoirs and should be recalculated according to the compositions of crude oil for the certain reservoir.

\section{Conclusions}

Based on the two-phase flash calculation theory of oil and gas, a novel approach was proposed to predict the EGR. PFVF of enriched gas was defined, and the logarithmic functions between the PFVF and GOR were established. As a consequence, the approach of EGR calculation for unconventional reservoir enriched gas displacement was obtained. The results obtained from this new approach were compared with that from numerical simulations, and the mean error is $12 \%$. In addition, the new approach can effectively avoid the influence of lean gas on the calculation of EGR.

Flash calculation results of different proportion of LPG in enriched gas show that when the proportion of LPG in the enriched gas is more than 50\%, the PFVF and GOR follow a logarithmic relationship; when the proportion of LPG in the enriched gas is less than 50\%, the PFVF and GOR follow another logarithmic relationship. Hence, the relationships between PFVF and GOR can be described by two functions. According to the different composition of the enriched gas, the corresponding function is selected to calculate the PFVF.

New approach has been used to calculate the EGR of enriched gas in three stages of enriched gas flooding in a low permeability and tight oilfield. The error is $5.62 \%$ compared to the results of field analysis data, which proves the correctness and practicability of this approach.

\section{Data Availability}

Data supporting the results of our study are in the article.

\section{Conflicts of Interest}

We declare that we do not have any commercial or associative interest that represents a conflict of interest in connection with the work submitted.

\section{Acknowledgments}

This study was carried out with the Open Fund of State Key Laboratory of Oil and Gas Reservoir Geology and Exploita- tion (Southwest Petroleum University) (Grant No. PLN2020-22) for its financial supports which we gratefully acknowledge.

\section{References}

[1] Y. Song, Q. Luo, Z. Jiang, W. Yang, and D. Liu, "Enrichment of tight oil and its controlling factors in central and western China," Shiyou Kantan Yu Kaifa/Petroleum Exploration and Development, vol. 48, pp. 421-433, 2021.

[2] L. Sun, C. Zou, A. Jia et al., "Development characteristics and orientation of tight oil and gas in China," Petroleum Exploration and Development, vol. 46, pp. 1073-1087, 2019.

[3] C. Yu, Q. Jiang, N. Su, and L. Chang, "Predicting the permeability of tight sandstone utilizing experimental and mathematical modeling approaches," Journal of Energy Resources Technology, Transactions of the ASME, vol. 143, no. 2, pp. 19, 2021.

[4] J. I. Lee, E. L. Astete, and T. F. Jerhoff, "Performance review of Brazeau River Nisku dry-gas miscible-flood projects," SPE Reservoir Engineering (Society of Petroleum Engineers), vol. 9, no. 1, pp. 29-34, 1994.

[5] L. Wang, Y. Tian, X. Yu et al., "Advances in improved/ enhanced oil recovery technologies for tight and shale reservoirs," Fuel, vol. 210, pp. 425-445, 2017.

[6] W. Chengjun and L. Xiaorui, "The empirical and theoretical miscible characterization method in gas-enhanced oil recovery," Geofluids, vol. 2018, Article ID 7841948, 9 pages, 2018.

[7] V. S. Rios, L. O. S. Santos, F. B. Quadros, and D. J. Schiozer, "New upscaling technique for compositional reservoir simulations of miscible gas injection," Journal of Petroleum Science and Engineering, vol. 175, pp. 389-406, 2019.

[8] A. Ebrahimi, E. Khamehchi, and J. Rostami, "Investigation of hydrocarbon and non-hydrocarbon $(\mathrm{CO} 2, \mathrm{~N} 2)$ gas injection on enhanced oil recovery in one of the Iranian oil fields," Technology, vol. 2, no. 4, pp. 209-222, 2012.

[9] L. L. Harbert, P. W. Reed, R. K. Bray, and J. N. Dew, "Progress report of LPG injection in the Meadow Creek Unit, Lakota B Reservoir," Journal of Petroleum Technology, vol. 11, no. 7, pp. 26-29, 1959.

[10] R. A. Fitch, "Experimental and calculated performance of miscible floods in stratified reservoirs," Journal of Petroleum Technology, vol. 16, no. 11, pp. 1289-1298, 1964.

[11] A. Hildenbrand, S. Schlömer, and B. M. Krooss, "Gas breakthrough experiments on fine-grained sedimentary rocks," Geofluids, vol. 2, no. 1, 23 pages, 2002.

[12] L. Xu, W. M. Ye, Y. G. Chen, B. Chen, and Y. J. Cui, "A new approach for determination of gas breakthrough in saturated materials with low permeability," Engineering Geology, vol. 241, pp. 121-131, 2018.

[13] F. Du and B. Nojabaei, "A diffusion-based compositionallyextended black oil model to investigate produced gas reinjection EOR in Eagle Ford," Fuel, vol. 306, article 121711, 2021.

[14] D. G. Raheem, B. Yilmaz, U. Kayahan, and S. Özdoğan, “Effect of recycled flue gas ratio on combustion characteristics of lignite oxy-combustion in a circulating fluidized bed," Energy and Fuels, vol. 34, no. 11, pp. 14786-14795, 2020.

[15] S. L. Yang, H. Chen, D. Z. Hang, H. Lu, X. Zhang, and S. B. Lv, "Mechanism of produced gas reinjection during CO2Flooding 
by chromatographic analysis," Journal of Dispersion Science and Technology, vol. 34, no. 3, pp. 342-346, 2013.

[16] H. Chen, S. L. Yang, S. S. Ren et al., "Crude oil displacement efficiency of produced gas re-injection," International Journal of Green Energy, vol. 10, no. 6, pp. 566-573, 2013.

[17] H. Yu, X. Lu, W. Fu et al., "Determination of minimum near miscible pressure region during $\mathrm{CO}_{2}$ and associated gas injection for tight oil reservoir in Ordos Basin, China," Fuel, vol. 263, article 116737, 2020.

[18] D. Cosovanu, M. Llovera, G. Villorbina, R. Canela-Garayoa, and J. Eras, "A simple and fast method for metabolomic analysis by gas liquid chromatography-mass spectrometry," Metabolomics, vol. 17, no. 2, 2021.

[19] S. T. Lee, H. Lo, and B. T. Dharmawardhana, "Analysis of mass transfer mechanisms occurring in rich gas displacement process," SPE Annual Technical Conference and Exhibition, no. article 18062, pp. 47-62, 1988.

[20] Y. Kawajiri, "Model-based optimization strategies for chromatographic processes: a review," Adsorption, vol. 27, no. 1, pp. 1-26, 2021.

[21] A. Lucia, B. M. Bonk, R. R. Waterman, and A. Roy, "A multiscale framework for multi-phase equilibrium flash," Computers and Chemical Engineering, vol. 36, pp. 79-98, 2012.

[22] A. Lucia, L. Padmanabhan, and S. Venkataraman, "Multiphase equilibrium flash calculations," Computers and Chemical Engineering, vol. 24, no. 12, pp. 2557-2569, 2000.

[23] W. X. Jin, S. C. Low, and S. C. M. Yu, "Some experimental observations on the single and multi-phase flow patterns in a model flash evaporation chamber," International Communications in Heat and Mass Transfer, vol. 26, no. 6, pp. 839-848, 1999.

[24] C. H. Whitson and S. B. Torp, "Evaluating constant-volume depletion data," Journal of Petroleum Technology, vol. 35, no. 3, pp. 610-620, 1983.

[25] R. M. Enick, G. D. Holder, and R. Mohamed, "Four-phase flash equilibrium calculations using the Peng-Robinson equation of state and a mixing rule for asymmetric systems," SPE Reservoir Engineering (Society of Petroleum Engineers), vol. 2, no. 4, pp. 687-694, 1987.

[26] D.-Y. Peng and D. B. Robinson, “A new two-constant equation of state," Industrial \& Engineering Chemistry Fundamentals, vol. 15, no. 1, pp. 59-64, 1976.

[27] P. Luo, W. Luo, and S. Li, "Effectiveness of miscible and immiscible gas flooding in recovering tight oil from Bakken reservoirs in Saskatchewan, Canada," Fuel, vol. 208, pp. 626636, 2017. 